\title{
Lots quality coverage survey technique for assessment of immunization performance and quality in an urban slum of Mumbai
}

\author{
Kalpak S. Kadarkar ${ }^{1}$, Shraddha R. Tiwari ${ }^{1}$, Gajanan D. Velhal ${ }^{2}$
}

\begin{abstract}
${ }^{1}$ Department of Community Medicine, Government Medical College, Aurangabad, Maharashtra, India
${ }^{2}$ Department of Community Medicine, Topiwala National Medical College, Mumbai, Maharashtra, India
\end{abstract}

Received: 16 October 2015

Accepted: 11 December 2015

\section{*Correspondence:}

Dr. Kalpak S. Kadarkar,

E-mail: kalpaksk@gmail.com

Copyright: (c) the author(s), publisher and licensee Medip Academy. This is an open-access article distributed under the terms of the Creative Commons Attribution Non-Commercial License, which permits unrestricted non-commercial use, distribution, and reproduction in any medium, provided the original work is properly cited.

\begin{abstract}
Background: The purpose of utilization of lot quality technique is to identify quickly \& scientifically the areas with poor performance and provide information for developing strategies to improve service quality. Evaluation of immunization coverage provides evidence whether substantial progress towards achieving immunization targets is being made. This study was conducted to assess immunization coverage and quality of immunization services as per mentioned in WHO's Lots Quality Survey Technique guide received by the child in view of appropriate age and interval in urban slum of Mumbai.

Methods: A cross-sectional, descriptive epidemiological study was carried out in the field practice area of urban health centre of institute during the period of January 2013 to December 2013. Total number of 336 children between age of 12-23 months were selected from 21 Lots by using standard lots quality survey technique. Data was analysed using SPSSv.16 with suitable statistical tests.

Results: The overall coverage of immunization in the urban slum area was $75.0 \%$ (fully immunized), $22.3 \%$ (partially immunized) and $2.7 \%$ (unimmunized). The immunization was received in $92.8 \%$ of children at inappropriate interval. Out of 21 lots 19 were unprotected.

Conclusions: Though the overall coverage of immunization was good in urban slum but still it has pockets of partial or non-immunization. In areas with high immunization coverage Lots Quality technique should be used to detect of poor coverage and quality and to take appropriate action.
\end{abstract}

Keywords: WHO, Lots, Community health volunteer, EPI, Mumbai

\section{INTRODUCTION}

In the past decade and half, all the districts in the country have been covered under the Universal Immunization Programme. However, providing immunization, by itself, does not guarantee a reduction in disease morbidity and mortality. The full course of vaccines must be given at the right age. WHO estimated that 1.5 million of deaths among children under 5 years were due to diseases that could have been prevented by routine vaccination in 2008. ${ }^{1}$ Despite routine immunization services, vaccine preventable diseases remain the important cause of childhood mortality. Uptake of immunization services is dependent not only on provision of these services but also on other factors including knowledge and attitude of mothers health status of child, density of health workers, accessibility to vaccination clinics and availability of vaccines, safe needles and syringes. ${ }^{2-4}$

Immunization coverage assessment helps to evaluate progress in achieving programme objectives and in improving service delivery. ${ }^{5}$ In addition, evaluation of 
immunization coverage provides evidence whether substantial progress towards achieving immunization targets is being made. Such positive evidence is required for continuing support from donor-supported initiatives like the Global Alliance for Vaccines and Immunizations (GAVI). ${ }^{6}$

This paper reports on a survey assessing immunization coverage for infants and factors impacting coverage in urban slum of Mumbai. Expanded program of immunization was launched in India in January 1978 and the Indian version, the Universal Immunization Programme (UIP), was launched in 1985 aimed at achieving universal immunization coverage of the eligible population. ${ }^{7}$ For infants vaccines provided under UIP are Bacille Calmette Guerin (BCG), diphtheria, pertussis and tetanus (DPT), oral polio (OPV), hepatitis B (HBV), measles. ${ }^{8}$ In India, only 44 percent of children age12-23 months are fully vaccinated, and 5 percent have not received any vaccinations in year 2005-06. ${ }^{9}$ Primary immunization coverage in Mumbai suburb was $72 \% .^{10}$ The difference between the percentages of children receiving the first and third doses is $21 \%$ for DPT , $15 \%$ for polio and 59\% of children age 12-23 months have been vaccinated against measles. The relatively low percentages of children vaccinated with the third dose of DPT and measles are mainly responsible for the low proportion of children fully vaccinated. ${ }^{9}$

Despite all efforts put by governmental as well as nongovernmental institutes for $100 \%$ immunization coverage, there are still pockets of low coverage areas. Urban slums constitute one of high risk areas for vaccine preventable diseases. ${ }^{11,12}$ Especially in urban areas there is increased reporting of vaccine preventable diseases, possibly due to migration leading to congestion and extra pressure on already overburdened health infra-structure of the cities. In order to find the unprotected pockets among the urban slum population, the present study was undertaken to assess the immunization coverage of children aged 12-23 months in urban slum and also the efforts were made to know the reasons for the delayed and non-immunization. Since lot quality sampling method requires only a small sample size and easier for staff to use, it is feasible for routine monitoring of vaccination coverage. ${ }^{13}$ The purpose of utilization of lot quality technique is to identify quickly \& scientifically the areas with poor performance and provide information for developing strategies to improve service quality.

\section{METHODS}

A cross-sectional, community based, descriptive epidemiological study was carried out in the field practice area (Shivajinagar urban health centre, Govandi, Mumbai) of the Topiwala National Medical College, Mumbai during the period of January 2013 to December 2013. The inclusion criteria for study subjects were all children between 12 months and 23 months of age with availability of either an immunization card or a responsible person for key information regarding immunization and who were permanent residents (residing for more than 6 months) of the study area. Mother and child not available at the time of actual visit to the respective home and children who do not satisfy above conditions were excluded from the survey purposes. The area was divided into 21 lots based on geographical service areas under 21 community health volunteers (CHV) functioning in health post. The study population comprised of all children aged 12-23 months. This age group was chosen for analysis because both International and Government of India guidelines specify that children should be fully immunized by the time they complete their first year of life. Children who received BCG, measles, and three doses each of DPT and polio (excluding polio 0) are considered to be fully immunized. Partially immunized child is one who has missed any one or more of the above doses irrespective of having received polio vaccination on Pulse polio days and a child who has not received even a single dose of any of the vaccines under UIP schedule other than polio vaccination on Pulse polio days is considered unimmunized. All the vaccines must be administered by the time the child is one year of age. Sample size for the study was calculated to be 336 , based on $5 \%$ level of accuracy and $95 \%$ level of significance. ${ }^{14}$ The estimated sample size for each lot was 16. A decision value (highest number of individuals in a lot not receiving a quality service and yet lot is acceptable) of 2 was selected based on lot sample size of 16 and low and high threshold set at $65 \%$ and $95 \%$, respectively. Trained investigators collected the information from 16 children in each lot. Only one child was selected from each household. Households were selected by simple random sampling method by using random number tables. Information regarding birth date, immunization card, dates of vaccines received, presence of BCG scar and reasons for incomplete or no vaccination was collected through pretested questionnaire and interview schedule. Dates of vaccines received were verified from office record in case vaccination card was not available. Response rate was $100 \%$. Criteria that meet the 'Quality' vaccination include those children who have received all vaccinations recommended in National immunization schedule at appropriate age and interval with presence of immunization card and BCG scar in those who received BCG vaccine. Information collected was analyzed to check number of children fulfilling the quality criteria of vaccination, lot-wise. Lot performance was judged unacceptable if it finds more than two children not accepting quality criteria. To get an overall single estimate of individual qualities of vaccination, data was aggregated from all 16 lots. Reasons for below quality immunization were analyzed in aggregate. The ethics committee of the institute approved the study. Socio economic status of the study population was determined as per the Modified Prasad's classification April 2013. ${ }^{15}$ Results were analyzed by using Statistical Package of Social Sciences (SPSS) version 16.0. Statistical significance was set at $\mathrm{P} \leq 0.05$. 
Table 1: Immunization coverage among various lots $(\mathrm{N}=336)$.

\begin{tabular}{|lllllllll|}
\hline Lot number & \multicolumn{2}{l}{ Fully immunized } & Partially immunized & Unimmunized & Total \\
& No. & $(\%)$ & No. & $(\%)$ & No. & $(\%)$ & 16 \\
\hline 1 & 12 & 75 & 4 & 25 & 0 & 0 & 0 & 16 \\
\hline 2 & 13 & 81.25 & 3 & 18.75 & 0 & 6.25 & 16 \\
\hline 3 & 14 & 87.5 & 1 & 6.25 & 1 & 12.5 & 16 \\
\hline 4 & 11 & 68.75 & 3 & 18.75 & 2 & 0 & 16 \\
\hline 5 & 12 & 75 & 4 & 25 & 0 & 12.5 & 16 \\
\hline 6 & 13 & 81.25 & 1 & 6.25 & 2 & 6.25 & 16 \\
\hline 7 & 12 & 75 & 3 & 18.75 & 1 & 0 & 16 \\
\hline 8 & 12 & 75 & 4 & 25 & 0 & 0 & 16 \\
\hline 9 & 11 & 68.75 & 5 & 31.25 & 0 & 6.25 & 16 \\
\hline 10 & 10 & 62.5 & 6 & 37.5 & 0 & 0 & 16 \\
\hline 11 & 14 & 87.5 & 1 & 6.25 & 1 & 6.25 & 16 \\
\hline 12 & 11 & 68.75 & 5 & 31.25 & 0 & 0 & 16 \\
\hline 13 & 13 & 81.25 & 2 & 12.5 & 1 & 6.25 & 16 \\
\hline 14 & 12 & 75 & 4 & 25 & 0 & 0 & 16 \\
\hline 15 & 13 & 81.25 & 2 & 12.5 & 1 & 0 & 16 \\
\hline 16 & 11 & 68.75 & 5 & 31.25 & 0 & 0 & 16 \\
\hline 17 & 11 & 68.75 & 5 & 31.25 & 0 & 0 & 16 \\
\hline 18 & 12 & 75 & 4 & 25 & 0 & 0 & 16 \\
\hline 19 & 11 & 68.75 & 5 & 31.25 & 0 & 0 & 16 \\
\hline 20 & 13 & 81.25 & 3 & 18.75 & 0 & 2.7 & 336 \\
\hline 21 & 11 & 68.75 & 5 & 31.25 & 0 & & \\
\hline Total & 252 & 75 & 75 & 22.3 & 9 & & 0 \\
\hline
\end{tabular}

\section{RESULTS}

Three hundred and thirty six children were surveyed under this study. Immunization coverage: $75 \%$ children were fully immunized, $22.3 \%$ were partially immunized and $2.7 \%$ were unimmunized. Immunization card was available with $84.9 \%$ caregivers/mothers. About $87 \%$ children were having BCG scar.

As evident from table 1, the number of children in lot sample not satisfying quality criteria (i.e. children who were partially immunized or unimmunized) were 2 in lot no. 3 and 11. As the number of children in lot 3 and 11 was less than or equal to decision value of 2 , performance of these lots was acceptable and lots were protected according to Lots Quality Survey Technique methodology. All remaining lots were unprotected and performance of these lots was not acceptable since children in lot sample not satisfying quality criteria were more than 2 . The percentage of fully immunized children in different lots ranged from $87.5 \%$ to $62.5 \%$. Maximum number of unimmunized children was present in Lot no. 4 and 6 (Table 1).

As observed from table 2, the overall coverage of different vaccine ranges from $97.87 \%$ for OPV 1 to $88.7 \%$ for Measles. The dropout rate was found to be $7.40 \%$ from BCG to Measles in study group. There was difference in coverage level of vaccines which are given in set (DPT,HBV,OPV) as first, second and third dose at 6th, 10th,14th weeks of age, due to non-availability of any vaccine (Table 2 ).

Table 2: Coverage levels of different vaccines by LQ coverage survey $(\mathrm{N}=336)$.

\begin{tabular}{|lll|}
\hline $\begin{array}{l}\text { Type of } \\
\text { vaccine }\end{array}$ & Received(frequency) & Received $(\%)$ \\
\hline BCG & 323 & 96.10 \\
\hline OPV0 & 293 & 87.2 \\
\hline OPV1 & 329 & 97.87 \\
\hline OPV2 & 323 & 96.20 \\
\hline OPV3 & 313 & 93.10 \\
\hline DPT1 & 327 & 97.40 \\
\hline DPT2 & 320 & 95.38 \\
\hline DPT3 & 312 & 92.89 \\
\hline HepB1 & 326 & 96.90 \\
\hline HepB2 & 320 & 95.10 \\
\hline HepB3 & 313 & 93.20 \\
\hline Measles & 298 & 88.70 \\
\hline Vitamin A & 295 & 87.90 \\
\hline
\end{tabular}


Table 3: Quality of immunization services $(\mathrm{N}=336)$.

\begin{tabular}{|c|c|c|c|c|c|c|c|c|c|c|c|c|}
\hline \multirow{2}{*}{ Type of vaccination } & \multicolumn{2}{|c|}{ BCG } & \multicolumn{2}{|c|}{ DPT1 } & \multicolumn{2}{|c|}{ DPT2 } & \multicolumn{2}{|c|}{ DPT3 } & \multicolumn{2}{|c|}{ MEASLES } & \multicolumn{2}{|c|}{ VITAMIN A } \\
\hline & No. & $\%$ & No. & $\%$ & No. & $\%$ & No. & $\%$ & No. & $\%$ & No. & $\%$ \\
\hline Not received vaccine & 13 & 3.9 & 10 & 2.98 & 16 & 4.76 & 24 & 7.14 & 38 & 11.31 & 41 & 12.20 \\
\hline Given on exact date & 28 & 8.3 & 4 & 1.19 & 4 & 1.19 & 02 & 0.60 & 115 & 34.23 & 117 & 34.82 \\
\hline $\begin{array}{l}\text { Given less than one year } \\
\text { but not on exact date }\end{array}$ & 295 & 87.8 & 314 & 93.49 & 313 & 93.15 & 302 & 89.88 & 172 & 51.19 & 168 & 50.0 \\
\hline $\begin{array}{l}\text { Given less than specified } \\
\text { time }\end{array}$ & 0 & 0 & 08 & 2.38 & 03 & 0.89 & 08 & 2.38 & 11 & 3.27 & 10 & 2.98 \\
\hline
\end{tabular}

*: means on exact dates as per national immunization schedule. E.g. $1^{\text {st }}, 2^{\text {nd }}, 3^{\text {rd }}$ dose of DPT on exact 6,10 , and 14 completed weeks respectively.

**: means before scheduled date. for example DPT1 given before $6^{\text {th }}$ completed weeks.

Table 3 shows, in a present study $3.9 \%$ of children had not received $\mathrm{BCG}$ vaccine and the dropout rate went on increasing from DPT1 $(4.76 \%)$ to DPT3 (7.14\%). The proportion of children who received vaccination as per national immunization schedule were found to be lower $(0.60 \%$ for DPT3 to $8.30 \%$ for BCG). Most of the children received vaccination in less than one year but not on appropriate time. This increased from BCG $(87.8 \%)$ to DPT3 $(89.88 \%)$. Total $40(11.90 \%)$ children received vaccines and vitamin $\mathrm{A}$ before the scheduled time which were $8(2.38 \%)$ for DPT1, 3(0.89\%) for DPT2, 8(2.38\%) for DPT3, 11(3.27\%) for Measles and $10(2.97 \%)$ for vitamin A. Median range for receiving DPT I and OPV I was reported to be 52 days (range: 42150 days). For BCG and Measles vaccine, reported median age was 9 days (range: 1-310 days) and 11 month (range: 7-15 months), respectively. Median dose interval of DPT/OPV between 1st \& 2nd dose was 32 days (range: 28-100 days) while it was 45 days (range: 28-140 days) between 2nd \& 3rd dose. Only $7.2 \%$ children received all vaccine at appropriate interval. The main The main reason for inappropriate interval was child being ill and not brought to hospital(17.53\%), followed by the child being to native place( $15.98 \%)$, unaware of need of immunization( $9.79 \%)$, mother too busy (7.22\%), postponed till another time $(6.19 \%)$, and fear of side effects (4.64\%) etc (Table 3).

\section{DISCUSSION}

In this study, immunization coverage was: $75 \%$ children were fully immunized, $22.3 \%$ were partially immunized and $2.7 \%$ were unimmunized, which is less than the desired goal of achieving $85 \%$ coverage. ${ }^{9}$ The present study shows higher immunization coverage $80.95 \%$ as compared to NFHS-III (2005-06) data $(43.5 \%) .^{9}$ It was due to efforts taken by health services in urban slum. Yadav et al revealed that percentage for fully immunized children was $73.3 \%$ and for partially immunized children it was $23.8 \%$, and for unimmunized it was $2.8 \% .^{16}$ Somewhat similar findings were seen in the study by Tapare et al at Miraj. ${ }^{17}$ Another study by Punith et al also found that overall vaccination coverage of completely immunized children was $92.10 \%$ and the percentage of partially immunized was $6.58 \%$, and unimmunized children accounted for $1.31 \% .{ }^{18}$ Similar level of coverage was also documented in other studies by Chaudhary et al, Kar et al and Khokhar et al in urban slums of Delhi and Ahmadabad city. ${ }^{19-21}$

Although overall coverage is good, the quality of services are not acceptable in some subgroups of population in the present study. As this study points out performance of immunization was not acceptable in 19 lots out of 21 lots. So corrective actions and interventions should be carried out in particular lot to improve reach, acceptability and quality of immunization services.

The coverage of individual vaccine was above $85 \%$, the set goal of Universal Immunization Program. Coverage

of individual vaccine was clearly more than percentage of fully immunized children. Reason behind this is definition of fully immunized children. Though all vaccines up to age of one year were not given to children in study population but individual vaccine could be given. Similar findings were noted in studies done by Malini Kar et al (2001) in south Delhi and Chaudhary et al (2010) in an urban area of Bareilly city. ${ }^{19,20}$ Study done by V S Tapare et al (2006) in Miraj showed different finding i.e. coverage for Measles vaccine was more than that of $\mathrm{BCG}$ vaccine. ${ }^{17}$

In a present study, the immunization was received in $92.8 \%$ of children at inappropriate interval. It was observed only in $7.2 \%$ of children, immunization was at right time and right interval. Similar finding was found in study done by Kulkarni et al (2013). ${ }^{22}$ Vaccination coverage of Measles is more than that of Vitamin A due to shortage of supply of Vitamin A at the health centre and anganwadis. Poor knowledge about immunization schedule and unaware about minimum interval between two subsequent doses of vaccines as well as improper history taking of immunization status of child are reasons behind immunization given less than specified time.

These variations in reasons for non-immunization in different areas and different studies might probably be due to variations in the literacy, socio demographic variation in different geographical locations, availability of health facility, efficiency of immunization services, 
lack of supervision and health monitoring systems across the country.

Since immunization is multi-sectoral activity, it definitely needs active intersectoral cooperation. Parents are to be educated about the importance of right time of immunization and maintaining immunization records and its role in the health of the child. Vigilant and frequent supervision and monitoring of immunization services is required. Timely reporting of new migrants by anganwadi workers will help to improve coverage at local level and reduce cases of non-immunization. Regular health education sessions and motivation through an encouraging and persuasive interpersonal approach, regular reminders and removal of misconceptions prevailing among people and improving the quality of the services at the health facility will solve the problems of delayed, partial and non-immunization. Pulse polio days should be utilized as a good opportunity for the advocacy of routine immunization to caregivers.

\section{CONCLUSION}

Though the overall coverage of immunization was good in urban slum but still it has pockets of partial or nonimmunization. In areas with high immunization coverage Lots Quality technique should be used to detect of poor coverage and quality and to take appropriate action.

\section{ACKNOWLEDGEMENTS}

1. Dr. S. R. Suryawanshi, Head of Department of Community Medicine, T.N. Medical college, Mumbai.

2. Dr. Dnyaneshwar Gajbhare, Asst. professor, TNMC Mumbai.

3. Dr. Yasmeen Kazi, Asst. professor, TNMC Mumbai.

4. Staff of UHTC and Health post, Shivajinagar, Govandi, Mumbai.

5. Post Graduate students, Department of Community Medicine, TNMC, Mumbai.

6. Study participants

Funding: No funding sources Conflict of interest: None declared

Ethical approval: The study was approved by the Institutional Ethics Committee

\section{REFERENCES}

1. WHO Factsheet. Available at: http://www.who.int/mediacentre / factsheets / fs378/en/. Accessed 7 November 2014.

2. Matsumura $\mathrm{T}$, Nakayama $\mathrm{T}$, Okamoto $\mathrm{S}$, Ito $\mathrm{H}$. Measles vaccine coverage and factors related to uncompleted vaccination among 18-month-old and 36-month-old children in Kyoto, Japan. BMC Public Health. 2005;5:59.
3. Torun SD, Bakirci N. Vaccination coverage and reasons for non-vaccination in a district of Istanbul. BMC Public Health. 2006;6:125.

4. Anand S, Bärnighausen T. Health workers and vaccination coverage in developing countries: an econometric analysis. Lancet. 2007;369:1277-85.

5. Bonu S, Rani M, Baker TD. The impact of the national polio immunization campaign on levels and equity in immunization coverage: evidence from rural North India. Soc Sci Med. 2003;57:1807-19.

6. Brugha R, Starling M, Walt G. GAVI, the first steps: lessons for the Global Fund. Lancet. 2002;359:435-38.

7. Park K. Textbook of Preventive and Social Medicine, 22 Ed. Jabalpur: Banarasidas Bhanot Publishers, Feb 2013:113-233.

8. Brief note on child health. Available at: http://nrhm.gov.in/images/pdf/media/publication/bri ef-note-on-child-health/brief note on ch nov 2011.pdf. Accessed 7 November 2013.

9. Introduction, Child Health, Maternal Health in National family Health Survey (NFHS-III), International Institute for Population Sciences publishers, Volume I, 2005-06; 198-278.

10. District Level Household Survey IV, 2012-13: Mumbai; 1-7.

11. The invisible child: A look at the urban child in Delhi. New Delhi: UNICEF; 1990.

12. Lodha R, Dash NR, Kapil A, Kabra SK. Diphtheria in urban slums in north India. Lancet. 2000;355(9199):204.

13. Jutand M, Salamon R. Lot quality assurance sampling: methods and applications in public health. Rev Epidemiol Sante Purlieu. 2000;48:401-8.

14. Monitoring immunization services using the lot quality technique, Geneva, World Health Organization. 1996:1-11.

15. An Updated Prasad's Socio Economic Status Classification for 2013. Int J Res Dev Health. 2013;1(2):26-8.

16. Yadav S, Mangal S, Padhiyar N, Mehta JP. Evaluation of immunization coverage in urban slums of Jamnagar city. Indian J Community Med 2006;31:300-1.

17. Tapare VS, Borle PS. Assessment of vaccination performance by lot quality technique in an urban community of Miraj. Indian $\mathrm{J}$ Community Med. 2006;31:182-5.

18. Punith K, Lalitha K, Suman G, Pradeep BS, Jayanth Kumar K. Evaluation of primary immunization coverage of infants under universal immunization programme in an urban area of Bangalore city using cluster sampling and lot quality assurance sampling techniques. Indian J Community Med. 2008; 33:151-5.

19. Chaudhary V, Kumar R, Agarwal VK, Joshi HS, Sharma M. Evaluation of Primary immunization coverage in an urban area of Bareilly city using Cluster Sampling Technique. NJIRM. 2010;1:10-5. 
20. Kar M, Reddaiah VP, Kant S. Primary immunization status of children in slum areas of south Delhi - The challenge of reaching the urban poor. Indian J Community Med. 2001; 26:151-4.

21. Khokhar A, Chitkara A, Talwar R, Sachdeva TR, Rasania SK. A study of reasons for partial immunization and non-immunization among children aged 12-23 months from an urban community of Delhi. Indian J Prev Soc Med. 2005;36:83-6.
22. Kulkarni SV, Chavan MK. A study to assess the immunization coverage in an urban slum of Mumbai by lot quality technique. Int J Med Public Health. 2013;3:21-5.

Cite this article as: Kadarkar KS, Tiwari SR, Velhal GD. Lots quality coverage survey technique for assessment of immunization performance and quality in an urban slum of Mumbai. Int J Community Med Public Health 2016;3:174-9. 